\title{
Multifunctionality of the oasis ecosystem. Case study: Biskra Oasis, Algeria
}

\author{
* Ph.D. Candidate FATMA ZOHRA HADAGHA ${ }^{1}$, Ph.D. Candidate BOURHANE EDDINE FARHI ${ }^{2}$, Dr. ABDALLAH \\ FARHI ${ }^{3}$, Dr. ALEXANDRU-IONUT PETRISOR 4 \\ 1 Habitat and sustainable cities, Faculty of Architecture, University of Biskra, Algeria \\ 2 Art of building and urban planning, University of Brussels, Belgium \\ ${ }^{3}$ Architecture and urban planning, University of Biskra, Algeria \\ ${ }^{4}$ Doctoral School of Urban Planning, "Ion Mincu" University of Architecture and Urban Planning, Bucharest, Romania \\ E mail: atimaz9193@yahoo.fr E mail: atimaz9193@yahoo.fr E mail: farhi.a@voila.fr E mail: alexandru_petrisor@yahoo.com
}

\begin{tabular}{|l|}
\hline A R T I C L E I N F O: \\
\hline Article history: \\
Received 15 July 2018 \\
Accepted 23 September 2018 \\
Available online 13 October \\
2018 \\
\hline Keywords: \\
Oasis ecosystem, \\
Ecosystem services, \\
Oasis multifunction. \\
\end{tabular}

This work is licensed under a Creative Commons Attribution - NonCommercial - NoDerivs 4.0. "CC-BY-NC-ND"

\section{A B S T R A C T}

The oasis, this green and ecological entity of the desert, a promise of life and hope in a rather unfriendly environment, has been for a long time a beneficial basis for the ecosystem services provided to human beings, for its socioeconomic and urban values, and also for its ecological value. Today many ideas and concepts are developed in the scientific literature to demonstrate the benefits derived from ecosystems, such as ecosystem services, multifunctionality, and ecosystem values. However, the analyses of multifunctionality or ecosystem services of the oasis lack from the scientific literature. This study uses a literature review and a prior assessment of the oasis ecosystem services in order to create a particular conceptual framework for the oasis in an attempt to create a toolbox of variables or indicators for the evaluation of ecosystem services in the particular case of a desert ecosystem, i.e., the oasis.

JOURNAL OF CONTEMPORARY URBAN AFFAIRS (2018), 2(3), 31-39. https://doi.org/10.25034/ijcua.2018.4716

\section{Introduction}

The oasis is a small area in the desert where the presence of water allows for cultivation (Larousse, 1982). The oasis is an area of sedentary life, which associates the city [medina] or village [ksar] with its surrounding feeding source, the palm grove, within a relational and circulatory nomadic system (Kouzmine, 2007). The oasis is also a sociospatial unit in the middle of the Saharan space, and also a distinctive mark of the cultural identity characteristic to a particular human settlement. It is important to clarify that the oasis is primarily a form of adaptation to the harsh physical conditions of arid environments. For centuries, the oasis has been able to overcome the major obstacles of the desert. The poor quality of the soil, the rise of salt, the problems of silting, the lack of access to water

*Corresponding Author:

Faculty of Architecture, Department of Architecture, Eastern

Mediterranean University, Famagusta, Northern Cyprus

E-mail address: atimaz9193@yahoo.fr 
resources and the inclemency of climatic conditions have not stopped the process of creating islands of greenery in the middle of the desert (Kerroumi, 2011). According to Ramad (2002), in the encyclopedic dictionary of ecology and environmental sciences, the oasis is a biotope located in a desert zone around a water point or in depressions where groundwater are close to the surface. According to Bouzaher (2015), the oasis is an ecosystem, traditionally structured by three fundamental elements, water, palm and habitat. Oases have played and continue to play a major role in the organization of space, the maintenance of the population and the economic functioning. This importance comes from the plurality of functions that oases have constantly fulfilled throughout history. The different functions provide to the oases, despite their limited size, a primary role in the development of Saharan and pre-Saharan territories (Kassah, 2010). Despite the importance of this ecosystem and its multiple functions, the oasis today is in a state of degradation. For that, this work aims to provide an answer to the following research question: How could the multiple roles of the oasis be demonstrated in order to challenge the degradation of its ecosystem services?

As the scientific literature lacks indicators of the ecosystem services of the oasis, we are interested in determining the major categories of benefits that the oasis society has derived from this ecosystem.

Much of the research has recognized many benefits of the urban vegetation, and most oasis-related research recognizes the fact that this ecosystem provides many different social, cultural, ecological and economic benefits.

The work of Selmi (2013), who explored the link between the two concepts, ecosystem services and multifunctionality, was used as a guiding frame for this article.

In this context, our study is based on a review of the scientific literature aimed at exposing a state of the art on the concept of multifunctionality and its relationship with the ecosystem services in the particular case of an oasis.

For this reason, we carried out a review of the scientific literature and an exploratory field survey aimed at accomplishing the following objectives:

- Collecting useful and relevant data for understanding the concept of the multifunctionality of the oasis, and ecosystem services.
- Acquire field observations and perform a qualitative assessment of the degradation of the oasis ecosystem.

The first step was to develop a study based on a qualitative approach, consisting of a documentary research, followed by a selective research focused on the contents of relevant documents (Fig. 1).

\begin{tabular}{l|l|l|}
\hline \multicolumn{1}{|c|}{ Literature research } & Evaluation / Selection \\
$\begin{array}{l}\text { Data base } \\
\begin{array}{l}\text { Books } \\
\text { Theses }\end{array}\end{array}$ & Reading of summaries \\
\end{tabular}

Fig. 1. Workflow of the review.

It is worth remembering that the main objective of this work is to show the link between the multiple functions of the oasis ecosystem and ecosystem services, in order to design a matrix of indicators for their evaluation, which can prove the degradation of the oasis ecosystem by the degradation of its services.

The study is not exhaustive, given the limits of research done on the topic of the oasis. This area is still under development and deserves to be developed. The objective of this work is to consider the different advantages of the oasis in several ways, as an attempt to enrich the theoretical and methodological contribution to this topic.

\subsection{Conceptual frame}

It was very necessary to understand, explicitly, the meaning of the notion of ecosystem services and also of the oasis ecosystem, by looking at their definition. Next, we classify the ecosystem services into several categories, and identify the components of the oasis ecosystem.

\subsection{Ecosystem services: exploration of the concept}

The notion of ecosystem services has become a topic of scientific debate in the international public spaces of biodiversity for some ten years now. Ecosystem services are the benefits that humans derive from the ecosystems. The Millennium Ecosystem Assessment was launched by the United Nations in 2001 to provide policymakers scientific information on the links between ecosystem change and human well-being, in order to define the actions required to strengthen the conservation of ecosystems and their exploitation in a sustainable manner. 
The literature review shows that the notion of the benefits of nature for humans produced was forged in the 1960s and 1970s in the United States. The concept of "ecosystem services" was then formalized among conservation biologists since the 1980s in order to draw global attention to biodiversity loss and ecosystem degradation. Then, the concept developed from a market perspective at the beginning of the 1990s through the development of ecological economics and research on payments for ecosystem services (Petrişor, 2016). The notion was publicized in France after the launch of the ecosystem assessment for the millennium between 2001 and 2005. After this time, the notion of "ecosystem services" was developed in the perspective of a very anthropocentric vision of nature (Cardona, 2014; Lamarque, 2012).

The notion of ecosystem services emphasizes first of all the dependence of man on his environment, but is based on finding out that the environment is destroyed on an alarming scale; this process leads to the question about the well-being of the man (Xavier et al, 2014).

\subsubsection{A Framework for the Ecosystem Services Analysis}

The Millennium Ecosystem Assessment (2005)

has proposed a classification of ecosystem services into four broad categories: provisioning services, which represent products and materials obtained from ecosystems such as water, food, fiber etc., regulating services which represent the benefits derived from the regulation of natural processes: climate regulation, watercourse regulation, disease and pest control, support services represent the services needed for the production of other services: soil formation, photosynthesis, nutrient and water recycling and cultural services refer to the non-material benefits provided by ecosystems and landscapes, aesthetics, places recreational activities (Lamarque, 2012).

Other classifications have been proposed subsequently, disrupting other categories according to the type of ecosystem. Groot et al (2002) developed an ecosystem services analysis framework based on the detailed analysis of natural elements and the introduction of value categories (Fig. 2). These authors identified four types of ecosystem functions that constitute a mixture of ecological processes, conservation issues, production and use of ecosystems and biodiversity for socio-cultural activities (Roche et al, 2016) (Fig. 3).

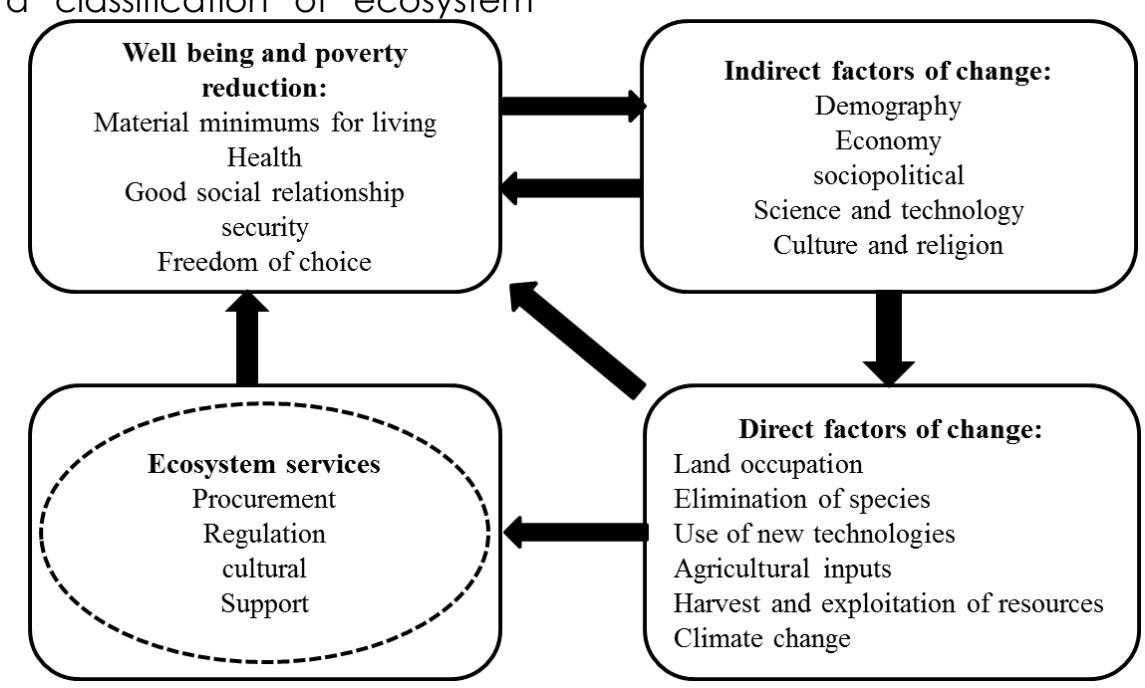

Fig 2. Framework for Ecosystem Services Analysis (Roche et al, 2016) 


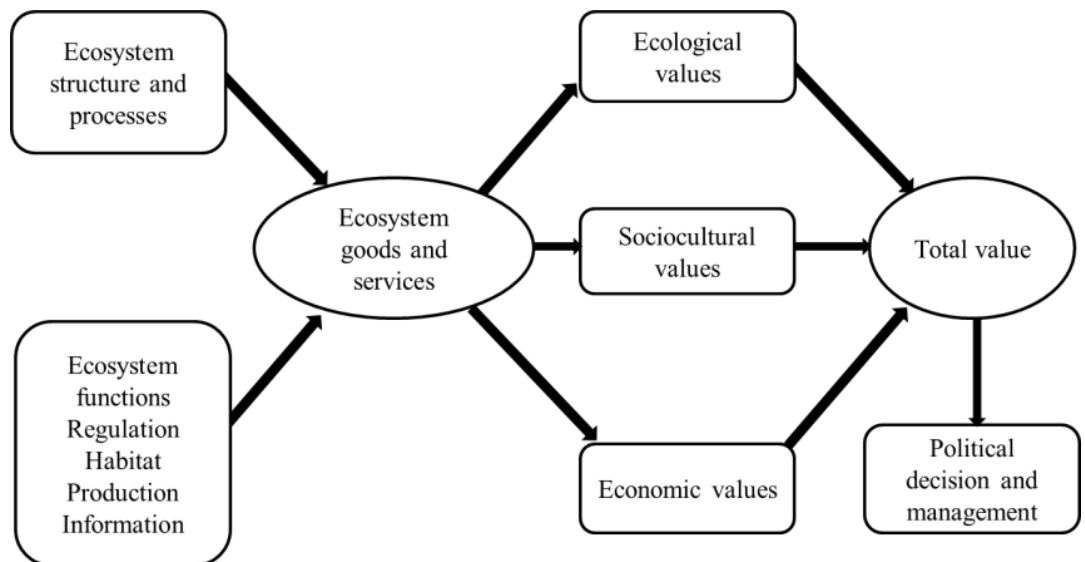

Fig. 3. Ecosystem flows and values, according to Groot et al., 2002 (Roche et al, 2016)

According to Zhang's model for agroecosystems (2007), we can distinguish three types of ecosystem services: input services, those that contribute to the supply of resources and the maintenance of physicochemical supports for agricultural production, and which ensure biotic interactions such as soil fertility, production services contributing to agricultural

\section{Input}

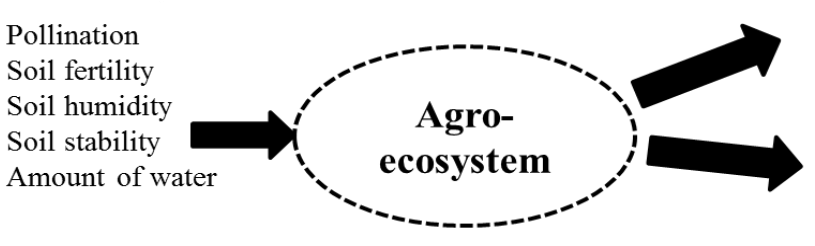

\section{Trader}

Feed quality

Feed quantity

Not-Trader

Climate regulation

Cultural values and aesthetics

Conservation of diversity

Diversity regulation

Regulation of natural risks

Water quality

Leisure

Fig. 4. Conceptual diagram of the services organization for an agro-ecosystem (Lamarque, 2012).

Another model of ecosystem services, which is also the most outstanding and widely used and disseminated in the scientific literature, has been developed by Haines-Young and Potschin (2010), and is referred as 'the cascade model' (Fig. 5). The phrase emphasizes the succession of levels that start from the ecosystem to the benefits for individuals and makes a clear distinction between the biophysical ecosystems, the ecological function, the ecosystem service and the benefit considered.

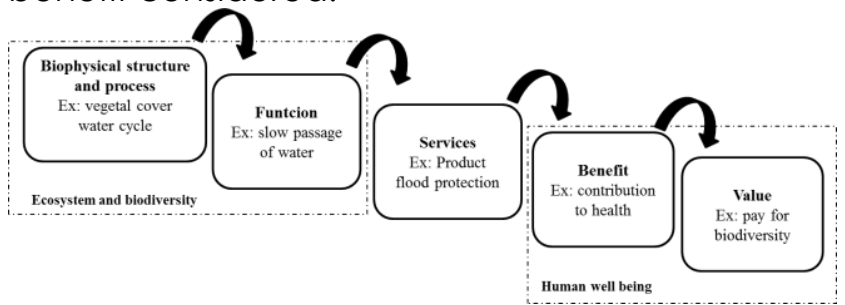

Fig. 5. Cascade model adapted from Haines-Young and Potschin (2010) (Source: Pesche and Méral, 2016).
However, the term 'ecosystem services' is a subject to many controversies, with respect to the confusion of the following terms: function, process, service, and benefit. For some authors (De Groot, 2002), 'function' refers to the ecological process of the ecosystem, and 'human well-being' refers to the benefit of the ecosystem, suggesting that ecosystem services are the result of the ecological functions of the ecosystem (Selmi, 2013).

Balmford and al. (2011) have developed a conceptual framework that extends the Millennium Ecosystem Assessment (MEA) ambition to make its previously developed framework more relevant and consistent with the proposal. The authors have classified ecosystem services in two categories: services that reveal fundamental processes of the ecosystem and those that are more directly useful to humans, by distinguishing between the ecosystem services and function (Fig. 6). 
Fisher, Turner, and Morling (2009) distinguished two categories of services: ecosystem-based processes, called intermediate services, and those that are directly useful to humans, called end-services (Pesche and Meral, 2016).

This review shows that the concept of "ecosystem service" has been the object of study of several researchers working in several fields and, there is a strong need for its conceptual development.

\begin{tabular}{|c|c|c|}
\hline $\begin{array}{c}\text { Essential ecosystem } \\
\text { process }\end{array}$ & $\begin{array}{c}\text { Beneficial ecosystem } \\
\text { process }\end{array}$ & $\begin{array}{c}\text { Beneficial ecosystem } \\
\text { process }\end{array}$ \\
\hline $\begin{array}{l}\text { Production } \\
\text { Decomposition } \\
\text { Nutrient cycle } \\
\text { Water cycle } \\
\text { Erosion } \\
\text { Ecological interaction } \\
\text { Evolutionary process }\end{array}$ & $\begin{array}{l}\text { Biomass production } \\
\text { Pollination } \\
\text { Biological control } \\
\text { Ecological interaction } \\
\text { Habitat formation } \\
\text { Variety of species } \\
\text { Waste assimilation } \\
\text { Soil formation } \\
\text { Regulation of erosion } \\
\text { Forming a pleasant } \\
\text { landscape } \\
\text { Regulation of air } \\
\text { quality } \\
\text { Climate regulation } \\
\text { Regulation of water } \\
\text { quality }\end{array}$ & $\begin{array}{l}\text { Food } \\
\text { Culture } \\
\text { Food product } \\
\text { Fresh water } \\
\text { Raw material } \\
\text { Energy } \\
\text { Manure } \\
\text { Infrastructure } \\
\text { Physical well being } \\
\text { Medicine derived } \\
\text { from cultured product } \\
\text { Pollution avoidance } \\
\text { Injury prevention } \\
\text { Psychological well } \\
\text { being } \\
\text { Tourism } \\
\text { Recreational activity } \\
\text { Spiritual well being } \\
\text { Aesthetic benefits } \\
\text { Nature observation } \\
\text { Green plants } \\
\text { Knowledge } \\
\text { Research } \\
\text { Education }\end{array}$ \\
\hline
\end{tabular}

Fig. 6. Framework and typology proposed by Balmford et al (2008) (Source: Pesche and Méral, 2016).

\subsubsection{Ecosystem services at the heart of environmental sciences}

In general, ecosystem and ecological services are often associated or even confused. They both refer to services that humans obtain from the nature. The concept of ecosystem services was considered more important by some ecologists in the 1970s in order to highlight the dependence of human societies on nature and the urgency of safeguarding the proper functioning of ecosystems.

This is how the social sciences have understood the genesis of the notion of ecosystem services and its dissemination, in order to better understand the changes that the concept could induce in public policies and decisionmaking.

In the late 1980s, a stream of ecological economics studies has revealed another aspect of the ecosystem services approach, addressing the general idea that the economic system is embedded into a larger system that has taken several names such as ecosystem, nature, or biosphere. This trend aims to assess biodiversity in a monetary and economic way, the anthropic pressures on biodiversity and the negative impact it has on economic activities and human well-being (Pesche and Méral, 2016).

Based on these results, we have oriented our work towards another perspective that is based on the three pillars of sustainable development and its relationship with the notion of ecosystem services, situated at the crossroads between the contribution of environmental science in the services ecosystem approach, the social and economic sciences and bring them together in a single evaluation grid afterwards.

\subsubsection{Sustainable development and ecosystem services}

Today, economics is particularly interested in the services provided by biodiversity (or ecosystems), i.e., the benefits that humans derive from nature (Bonnet and Curri, 2012). Sustainable development reconciles man, economy and the environment in a circle of interdependence, and attempts to ensure a sound and reasonable management of resources, without harming the environment and human.

In order for the development to be sustainable, society must use the natural resources at a rate that allows them to recover naturally. The quantity and quality of ecosystem services obviously play a crucial role in this process. The use and sustainable management of ecosystems are also at the heart of poverty reduction actions. Ecosystem services are an integral part of poor people's lives, and their degradation or loss can have a devastating impact on both the well-being of the poorest and on the efforts to reduce the incidence of poverty (Kosmus, Renner, Ulrich, 2013).

In the public debate and scientific literature dealing with environmental issues, the very broad concept of sustainable development has been supported by the notion of ecosystem services, which accounts for the link between humans and the ecosystems around them (Petrişor, 2017). Although this concept is slightly different from 'sustainable development', the notion of ecosystem services specifies the form of human-nature relationships, by proposing a detailed nomenclature of the different forms of services provided to the human society by nature. This enables highlighting the links between the urban form and environment: urbanization can have detrimental, but also beneficial effects depending on the type of ecosystem services studied (Regnier, 2017).

It seems clear that the nation of 'ecosystem services' has a broad relationship with 
sustainable development, as the services provided by nature or any kind of ecosystem must be used in a reasonable way in order to maintain the living standards of current generations by turning them into beneficiaries of the natural ecosystems, and also ensure the survival of the future generations by protecting the natural resources in order to meet their needs.

\subsubsection{Sustainable planning and ecosystem services}

The city offers the best chances to establish a sustainable development approach based on the protection of biodiversity, respect of its rhythm and maintenance of ecosystem services provided by it (Selmi, 2014). The city is the basis of all types of urbanization projects. Recently, in terms of sustainable development, urbanization projects are subject to evaluation by certain tools, in order to verify their sustainability performance and the compliance with the objectives, targets and requirements of sustainability. These tools guide the action, step by step, helping to organize the process of retaining what is important, and providing options for tailored solutions. The implementation of these tools requires understanding and analyzing the phenomenon and then setting sustainability targets. Today many researchers and urban practitioners are building evaluation tools using the ecosystem services approach.

In the context of the worldwide accelerated urbanization, understanding the inter-relational complexity between humans and the urban environment has become a key concern. For this purpose, some studies have recognized the fundamental role that biodiversity plays in the city. The ecosystem services approach is integrated into urban planning policies in Europe, and this approach is clearly identified as a tool for building good resilience of cities and improving the quality of life (Pesche and Méral, 2016; Petrişor et al., 2016).

According to Bonnet and Curri (2012), understanding the value of ecosystems can lead to more informed and potentially different decisions. Taking into account the fact that this value can lead to a better management, investments in natural capital can be very profitable and sharing the benefits of these actions can generate real benefits for the most disadvantaged.

The analysis of ecosystem services is essentially based on the analysis of the values and benefits of a natural, semi-natural or urban ecosystem. These values are diverse: social, cultural, spiritual, economic or ecological. The choice of the values to be analyzed remains dependent and determined by the researcher who carries out the evaluation of the ecosystem services; in addition, the evaluation methods are also diverse.

According to Breault (2014), the economic valuation of ecosystem services is one of the decision support tools, although it is only one element of an entire toolkit designed to help decision-making. It represents the particular advantage of associating a monetary value with the non-market services provided by urban ecosystems. This value is directly usable for evaluating the costs and benefits of urbanization projects leading to changes in the flow of ecosystem services delivered to the community, and to assess the required compensation if there is a net loss of these.

All of the above demonstrate that even though the ecosystem services approach is recent, many practitioners have put in place attempts related to sustainable management. As an example, Selmi (2014) has tried to develop an approach for evaluating the functioning and ecosystem services provided by the natural components of the city, or more specifically the analysis of urban green spaces based on their ecosystem services. Regnier (2017) has linked the problem of urban sprawl to the ecosystem services rendered by the urban ecosystem, in order to finally propose an urban form compatible with the preservation of the environment. Breault (2014) has attempted to set up economic evaluation tools and payment programs for the provision of ecological services in urban areas. This indicates the importance and interest in using the approach of ecosystem services in the field of sustainable development.
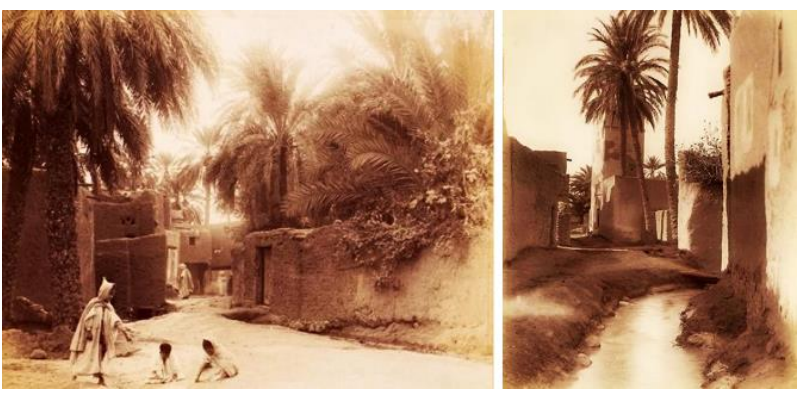

Fig. 7. Traditional oasis landscape

\subsubsection{The oasis and ecosystem services}

If there is a place that symbolizes human life in the desert, this is the oasis. The development of the cultivation of several varieties of dates, and, more recently, the cultivation using greenhouses, have favored the marketing of 
oasis agricultural products. Oases have been integrated more and more into the market economy and international trade.

The oasis systems are characterized by a great diversity and carry multiple functions: agricultural or productive function, strategic or territorial function, recreational or tourist function, symbolic or identity function. Water appears to be an asset and major constraint and determines the development strategies for the future in the form of technological innovations and bold choices between: a qualitative leap associated with stabilization or a reduction of surfaces (strategy of the hedgehog) and a quantum leap in extension and creation of new oases (bull strategy) (Kassah, 2010).

It is very clear that the oasis is an ecosystem that offers a lot of benefits for man and the maintenance of his life and well-being. This is a perfect model of sustainable development thanks to its ecological peculiarities, its economic function in favor of a society well adapted to the desert context through the services and benefits provided by the oasis.

\subsubsection{Cross look at the multifunctionality and services of the oasis ecosystem}

Given the scarcity of work done on the roles and benefits of the oasis ecosystem and its services, we have tried to search for writings and documents that have addressed the oasis not only in terms of urban planning, but also in economic and ecological terms, in order to get an idea about its functions and the role it plays at different levels.

According to several researchers (Bouzaher, 2015; Lakhdari and Cote, 2012; Zekri, 2011; Kassah, 2010; Brunel, 2006; Collete and Riou, 1990), the oasis represents a green island in the desert, a symbiosis between humidity, heat and light, a biodiversity reservoir due to its rich flora and fauna, all making together a the system used for shelf culture and breeding practices that maintain the soil fertility. The latter is maintained by cyclic organic inputs of animal origin, but also by the use of the shelf culture system.

In addition, the palm tree, as long as a characteristic oasis species aes used for ecological purposes, protects the trees and plants that are positioned on the lower floors, and also acts as a stabilizer and crop regulator. It is also used as an umbrella to protect plant species below from atmospheric aggressiveness, such as solar rays, and creates favorable conditions for their cultivation. Because of its density, it prevents the drought of soil, improves the water reserve in the dried grounds, allowing for the maintenance of soil moisture, and mitigates the damage of natural hazards such as the sandstorms, leading to the improvement of the climatic conditions of the living environment.

The palm grove, as an ecological unit, can play a windbreak role, limiting the advancement of the desert, acting against desertification, by fixing large amounts of dust. As long as a wetland or water exists either on the surface (visible at the seguia level) or at the level of the water table, the oasis plays a bioclimatic role due to the presence of water and palm groves, contributing to the evapotranspiration. Measurements taken in different oases have showed that the potential evapotranspiration of the areas was reduced by 30 to $50 \%$ within the oasis. This is called "the oasis effect", and tempers the desert severity inducing a microclimate favorable to crops (wind reduction, shading and evapotranspiration).

The palm grove constitutes the fundamental element of the oasis ecosystem and provides the agricultural character of oasis social life. It is the main source of income and employment in the economy, and improves the incomes of the inhabitants thanks to the production of dates and the development of underlying crops up to 3 stages of vegetation, providing a diverse food production. Secondary crops contribute significantly to the nutritional balance and improvement of family incomes; in all oases, a peasant spot is reserved at the local market for the sale of the palm grove products. Tomatoes, fresh salad and alfalfa can all be found here, as well as aromatic plants, and always these products have an exceptional quality. It should also be noted that this practice is at the origin of a conservation of the agro-biodiversity of local species, acclimated to the conditions of the desert environment. However, this particular biotope is an exotic treasure and encourages tourism, which is its strategic function and also contributes to the economic development of oasis communities.

From a social viewpoint, the palm grove plays a major role in the lives of the inhabitants by ensuring the social stability of the populations living in the oases. This contributes to the conservation of traditional knowledge and know-how that allow for a judicious and sustainable use of natural resources, be it water, irrigation techniques, or biodiversity, with respect to the choice of adapted crops. Thus, it promotes the maintenance of the psychic and 
psychological balance of the human being by positively influencing their living environment and health.

The palm grove is a natural refuge of pure air where the oasis man finds a positive psychological effect and a favorable response to his need for rest and relaxation. Due to its utilitarian function, the palm grove, like any other green space, plays an ornamental role by contributing to the beautification of the oasis landscape. The palm tree is also a constructive element and often offers planks, poles, beams, lintels and decorative fences. Under the light of all its functions and its services, the oasis, through its palm grove, contributes to the psychological comfort and human well-being.

Table 1. Example of works dealing with the functions and roles of the oasis.

\begin{tabular}{|c|c|c|}
\hline \multicolumn{3}{|c|}{ Oasis ecosystem roles and functions (work) } \\
\hline Author & & Function and role \\
\hline $\begin{array}{l}\bullet \\
\text { er (2015) }\end{array}$ & Bouzah & $\begin{array}{ll}-\quad & \text { Environmental role } \\
-\quad & \text { Social role } \\
-\quad & \text { Economic role } \\
- & \text { Architectural and urban role }\end{array}$ \\
\hline $\begin{array}{l} \\
(2010)\end{array}$ & Kassah & $\begin{array}{ll}- & \text { Agricultural function } \\
- & \text { Strategic function } \\
- & \text { Recreational function } \\
\text { - } & \text { Cultural function } \\
\end{array}$ \\
\hline$\bullet$ & Colette & $\begin{array}{l}\text { Environmental role } \\
\text { Economic and social role } \\
\text { Heritage role }\end{array}$ \\
\hline $\begin{array}{l} \\
\text { (2011) }\end{array}$ & Zekri & Recreational value \\
\hline al (2009) & Boudjell & Environmental role \\
\hline $\begin{array}{l} \\
\end{array}$ & Zhao & Environmental role \\
\hline $\begin{array}{l} \\
(2006)\end{array}$ & Brunel & Ecological role \\
\hline $\begin{array}{l} \\
\text { (1990) }\end{array}$ & Riou & Ecological role \\
\hline
\end{tabular}

The literature review on the oasis was synthesized in Table 1, summarizing the roles and functions of the oasis, and Table 2, based on the ecosystem services classified into four types, ecological, economic, socio-cultural and urban.

Table 2. Oasis ecosystem services board.

\begin{tabular}{|c|c|}
\hline \multicolumn{2}{|c|}{ Oasis ecosystem services } \\
\hline Type & Service \\
\hline gical type & $\begin{array}{l}\text { Maintaining soil humidity } \\
\text { Wind breeze effect } \\
\text { Nutrient recycling } \\
\text { Compost production } \\
\text { Maintaining soil fertility } \\
\text { Limit of the desert advance } \\
\text { Solar radiation reduction } \\
\text { - } \quad \text { Temperature control } \\
\text { evapotranspiration } \\
\text { - } \quad \text { Resistance to damage } \\
\text { caused by storms } \\
\text { Fixing the dust by the fins }\end{array}$ \\
\hline
\end{tabular}

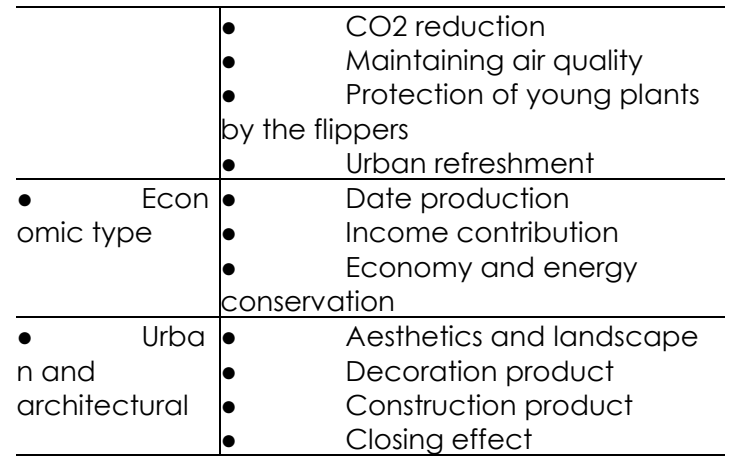

\section{The establishment of a green oasis frame}

The evaluation of ecosystem services provided by the oasis and its multifunctionality may be useful if this evaluation is used to justify the choice of plant and the design criteria in a Saharan context. This operation tends to mobilize certain ecological issues, such as the conservation of oasis biodiversity, and certain socio-cultural issues, such as the conservation of traditional knowledge.

\section{Conclusion}

The oasis is a natural ecosystem specific to the desert. From an ecological point of view, this ecosystem is multifunctional, given the diversity of services it provides to society.

The ecosystem services of the oasis are in a state of degradation due to several factors. For this reason, this work is only a simple initiative to define the ecosystem services of the oasis, in order to increase the awareness by underlining the losses of oases over time, and also to determine the decision-makers and planners paying attention to the importance of the oasis attributes during design and development operations.

\section{Acknowledgment}

I would like to express my sincere thanks to assist my supervisors, prof Abdallah FARHI, and prof Alexandru lonut PETRISOR who lead me to give my best and my colleague Bourhane Eddine FARHI for his collaboration and help in this simple work.

\section{References}

Bouzaher, S. (2015). Un aménagement durable par un projet écotouristique Cas des ksour de la micro région des Ziban. Le redressement d'un circuit écotouristique [Sustainable development through an ecotourism project, Ksour case of the Ziban micro region[. Thesis, University of Biskra. Availible at: http://thesis.univ-biskra.dz/1393/ Boudjellal, L. (2009). Role of the oasis in the creation of freshness island in hot and arid 
areas. Thesis, University of Constantine. https://bu.umc.edu.dz/theses/architecture/ BOU6126.pdf

Selmi, W., Weber, C., \& Lotfi, M. (2013). Multifunctionality of urban green spaces. The electronic journal in environmental sciences $13 \quad$ (2), $\quad$ Quebec. https://www.erudit.org/en/journals/vertigo/2 013-v13-n2-vertigo01504/1026436ar/

Zhao, W. \& all (2008). Shielding effect of oasisprotection systems composed of various forms of wind break on sand fixation in an arid region. ecological engineering 33 (119125), Elsevier. https://doi.org/10.1016/j.ecoleng.2008.02.01 $\underline{0}$

Kassah, A. (2010). Oasis and development in arid zones, Issues, Challenges and Strategies. article, Hall, open access archives. https://core.ac.uk/download/pdf/39836564. $\underline{\mathrm{pdf}}$

Brunel J-P. \& all (2006). Energy budget and actual evapotranspiration of an arid oasis ecosystem: Palmyra (Syria). Agricultural water management $84\left(\begin{array}{llllll}2 & 1 & 3 & - & 2 & 2\end{array}\right)$, Elsevier. https://doi.org/10.1016/i.agwat.2006.02.005

Hanafi, A. \& Alkama, D. (2017). Role of urban vegetal in improving the thermal confort of a public spaces in a contemporary Saharan city. Energy Procedia 119 (139 - 152), Elsevier. https://ac.elscdn.com/S1876610217326036/1-s2.0S1876610217326036main.pdf? tid=b1676aa0-4lea-4da8-acld517b590f6353\&acdnat $=1544119485$ 97deb9 e0bfd7a840965d66cdf6balcae

Riou, C. (1990). Bioclimatology of oases, Oasis farming systems. Montpellier, Mediterranean options, n.11 p. $207 \quad-2 \quad 2 \quad 0$, CIHEAM. https://www.cabdirect.org/cabdirect/abstr act/19916778179

Roche, P. (2016). Values of biodiversity and ecosystem services, Book, Editions Quae. https://www.ecologic.eu/13716

Meral, P \& Denis Pesche (2016). Ecosystem services, Rethinking nature and society, Book, Editions Quae. https://www.researchgate.net/publication/ 303583655 Soil_Ecosystem_Services_and_Na tural_Capital_Critical_Appraisal_of_Researc h_on_Uncertain_Ground 